\title{
Performance Evaluation of Different Air Venting Methods on High Pressure Aluminum Die Casting Process
}

\author{
E. AltunCU ${ }^{a, *}$ A. DoĞAN ${ }^{a, b}$ AND N. EKMEN ${ }^{b}$ \\ ${ }^{a}$ Sakarya Applied Sciences University, Department of Metallurgy and Materials Eng., Sakarya, Turkey \\ ${ }^{b}$ Arpek Arkan Aluminum Injection and Die Industry, Kocaeli, Turkey \\ In the automotive industry, die casting technology is used in the production of many parts in series. Due \\ to increased customer demands and reliability expectations, tightness properties are dominant in aluminium alloy \\ based cast parts. In order to acquire the tightness property, it is necessary to control the gas porosity at the casting \\ structure. High pressure die casting aluminium alloy products generally contain gas porosity in certain sizes and \\ ratios due to gas compression during high speed injection of molten metal into the die cavity. Proper die design \\ and evacuation of air in the die and also optimized process parameters need a very critical precaution to reduce \\ the gas porosity. Today, various venting, valve, and vacuum systems are used to facilitate the evacuation of die air. \\ The use of venting systems in the process increases both product quality and process efficiency. In this study, the \\ performance of $3 \mathrm{D}$ venting system and mechanical valve performance in high pressure aluminium alloy (AlSi10Mg) \\ casting process with cold chamber were compared on MAGMASOFT high pressure die casting simulation program. \\ As a result of the experimental studies of the 3D vents system, the gas porosity and machine shutdown times can \\ be significantly reduced.
}

DOI: 10.12693/APhysPolA.135.664

PACS/topics: die casting, aluminium alloy, efficiency, gas porosity, vent

\section{Introduction}

In the automotive industry aluminium alloys are often preferred as the material in parts that provide significant advantages such as lightweight, attractive appearance, excellent machinability, and high corrosion resistance $[1,2]$. In particular, the aluminium silicon copper (Al-Si-Cu) cast alloys are widely used in different application fields because of their good castability. Different manufacturers are using various casting processes for the manufacture of aluminium automotive parts. High pressure die casting (HPDC) is one of the most commonly used casting method for aluminium alloys [1,3]. HPDC is a cost-effective process widely used to produce components with forming capability of complex shaped castings with fine grain microstructure, as well as excellent surface and excellent dimensional accuracy [3-5]. Although the tooling is expensive, the productivity is high and part price is thereby modest. As such the process is highly popular, so that over $50 \%$ of all $\mathrm{Al}$ alloy castings are produced by HPDC [5].

The most important casting defect in HPDC processes is porosity, which is generally encountered due to process parameters, die properties, and casting alloy. Two types of porosity, shrinkage porosity and gas porosity, affect the quality of the casting parts. The shrinkage porosity is often caused by the formation of porosity due to solidification, whereas the gas porosity is due to the pressure casting mold design, the process parameters, and the venting

\footnotetext{
*corresponding author; e-mail: altuncu@subu.edu.tr
}

performance. According to Walkington's article [6], there are four reasons for the gas porosity in die casting which are trapped air, trapped steam, gas from vaporized lubricant, and hydrogen gas. Gas porosity from hydrogen level and air entrapment is always a factor in molten aluminium, and it is a major source of trapped gas in aluminium casting methods. The solubility of hydrogen in molten die casting aluminium is very high, whereas air entrapments from turbulent flow are the main factors affecting casting quality. It has been demonstrated that when the vacuum technology is applied correctly, these procedures can reduce the gas content.

From past to present, many venting systems have been used in HPDC method. Initially, conventional method were used, with air gaps. In the later applications, chill vents were started to be used. Conventional chill vents are commonly used in the die casting industry to ventilate air from the die cavity through a corrugated gap. Conventional chill vents can be used with vacuum, but their weakness is that the small evacuation area restricts the rate of air evacuation. Typically the gap is less than $1 \mathrm{~mm}$ in depth and about $100 \mathrm{~mm}$ in width. It can also be used as a vacuum valve when it is connected to a vacuum system [7]. In the following years mechanical vacuum valves began to be used. This type of valve is shut off mechanically by the metal impact or by sensing the metal front during the very last stages of cavity filling. The mechanical type of valve is highly efficient. However, it has been observed that machine shutdown times are very high in processes using mechanical vacuum valves. Wang et al. [8] reported that the cost includes the spare parts for the valve, the repair, and cleaning of the valve and the capital cost to purchase the valve has been the biggest contributor to the cost of casting. 
In recent years, three-dimensional valve systems have been developed and used in automotive high pressure casting systems. These systems can be used both as a vent and as a vacuum valve. Wang's study showed that [8-10], 3D venting systems, when used as a vent, is more efficient than a conventional chill vent which connected to a vacuum system, and can achieve nearly the same evacuation efficiency as the best available from a simple vacuum system. In another study, Wang et al. [8] showed that $3 \mathrm{D}$ venting systems, when used in the die casting process, then the machine downtime which is caused by vacuum defects has been reduced.

\section{Experimental procedure}

This study used $\operatorname{AlSi} 10 \mathrm{Mg}(\mathrm{Fe})$ alloy, which is one of the most commonly used aluminium alloy in HPDC alloys. A complex compressor part was selected to observe performance of all air venting systems. In this study, different venting methods were meshed on MagmaSoft HPDC simulation software in order to check evacuation performance of $3 \mathrm{D}$ venting system and mechanical valve performance in high pressure die casting process. Selected casting parameters for filling simulation is given in Table I. This study included velocity, temperature, and time during the filling for $3 \mathrm{D}$ venting system and mechanical valve system.

TABLE I

Casting parameters of process for filling simulation

\begin{tabular}{c|c|c|c|c}
\hline \hline $\begin{array}{c}\text { Initial } \\
\begin{array}{c}\text { temperature } \\
{\left[{ }^{\circ} \mathrm{C}\right]}\end{array}\end{array}$ & $\begin{array}{c}\text { Die } \\
\text { preparation } \\
\text { time }[\mathrm{s}]\end{array}$ & $\begin{array}{c}2 . \text { phase } \\
\text { velocity } \\
{[\mathrm{m} / \mathrm{s}]}\end{array}$ & $\begin{array}{c}\text { Working } \\
\text { pressure } \\
{[\mathrm{bar}]}\end{array}$ & $\begin{array}{c}\text { Ejection } \\
\text { time }[\mathrm{s}]\end{array}$ \\
\hline 660 & 16 & 4 & 600 & 5
\end{tabular}

\section{Results and discussion}

The results were calculated in accordance with venting efficiency of the mold by comparing filling temperature and filling velocity parameters. The results showed that there are significant differences between the mechanical valve and the $3 \mathrm{D}$ venting systems (Fig.1). These differences calculated via MagmaSoft simulation program are given in Table II.

Values of parameters on venting systems

TABLE II

\begin{tabular}{l|c|c|c|c}
\hline \hline System type & $\begin{array}{c}\text { Venting } \\
\text { area } \\
{\left[\mathrm{mm}^{2}\right]}\end{array}$ & $\begin{array}{c}\text { Filling } \\
\text { time } \\
{[\mathrm{ms}]}\end{array}$ & $\begin{array}{c}\text { Input } \\
\text { temperature } \\
{\left[{ }^{\circ} \mathrm{C}\right]}\end{array}$ & $\begin{array}{c}\text { Input } \\
\text { velocity } \\
{[\mathrm{m} / \mathrm{s}]}\end{array}$ \\
\hline mechanical valve & 19.5 & 3 & 618 & 60 \\
3D venting system & 120 & 10 & 598 & 48
\end{tabular}

Most commonly used mechanical valve had venting area of just $19.5 \mathrm{~mm}^{2}$ although the total area was $160 \mathrm{~mm}^{2}$. This value was too low when compared to a chill block. In addition, the flowing metal temperature at the inlet of the valve was about $610^{\circ} \mathrm{C}$ and the metal flow speed is higher than $60 \mathrm{~m} / \mathrm{s}$ (Fig. 2). 3D venting system had venting area of $120 \mathrm{~mm}^{2}$, and starts filling up at nearly to $60 \mathrm{~m} / \mathrm{s}$ and begins to fill at relatively low temperatures of $560^{\circ} \mathrm{C}$ (Fig. 3).
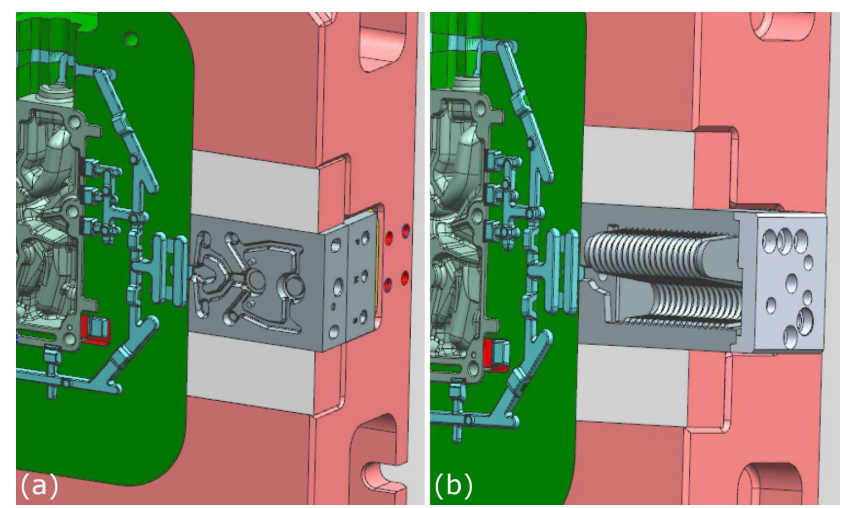

Fig. 1. Illustration of mechanical valve (a) and 3D venting systems (b) on the die.

\begin{tabular}{llllll} 
(a) $\quad 42.86$ & 47.14 & 51.43 & 55.71 & 60.00 \\
\hline
\end{tabular}
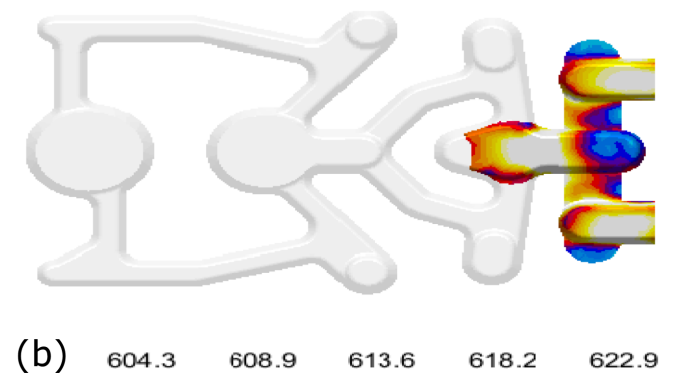

$\begin{array}{lllll}\text { (b) } 604.3 \quad 608.9 & 613.6 & 618.2 & 622.9\end{array}$

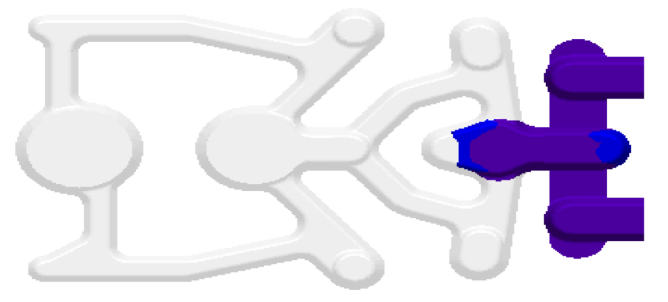

Fig. 2. (a) Filling velocity and (b) filling temperature results of the mechanical valve system inlet.

Due to the high temperature and high speed, the valve filling started at $2.203 \mathrm{~s}$ and ended at $2.206 \mathrm{~s}$ of the process. In addition to this, $3 \mathrm{D}$ venting system filling started at $2.197 \mathrm{~s}$ and ended at $2.207 \mathrm{~s}$ of the process.

There were $7 \mathrm{~ms}$ difference in terms of filling times of the two systems. Considering the working mechanism, the filling time of $3 \mathrm{~ms}$ is not enough. This is due to the fact that, when the metal valve arrived at the first piston to operate the closing mechanism, there was just $2 \mathrm{~ms}$ for closing (Fig. 4b). When the metal started to 
$\begin{array}{llllllll}\text { (a) } & 34.29 & 38.57 & 42.86 & 47.14 & 51.43 & 55.71 & 60.00\end{array}$
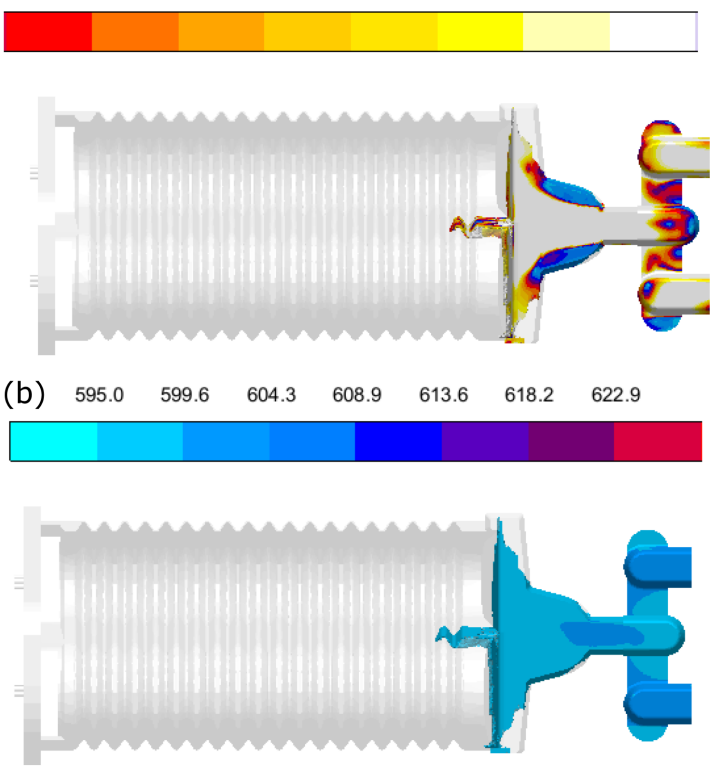

Fig. 3. (a) Filling velocity and (b) filling temperature results of the $3 \mathrm{D}$ venting system inlet.

move from the first piston to the gas throwing area, it was seen that the velocity and the temperature of metal were high and it was not possible to be solidified during the process. This is in contrast with the fact that, $3 \mathrm{~ms}$ after the process started, the temperature of the metal in the 3D venting system was close to the solidification temperature and the velocity was twice slower than the other system (Fig. 4c).

Foundry experiences have shown that each venting system is blocked after a period of use and requires cleaning. These blockings cause production stoppages. The metal velocity in the venting system increases and filling happens nonhomogeneously due to the reduction of the crosssection caused by the blockings. Therefore, mechanical valve systems have enough section area.

\section{Conclusion}

The following conclusions are drawn from the present investigation. When the metal started to move from the first piston to the gas throwing area, it was seen that the velocity and the temperature of metal were high and it was not possible to solidify it during the process. That is why it is difficult for the mechanical system to work efficiently. Ineffective working of the mechanical valve and blocking cause production stops. Thus increasing production costs. Another disadvantage of mechanical valve is high maintenance cost and the difficulty of cleaning. On the other hand, 3D venting systems have advantage of low blocking difficulty and low maintenance need, and therefore, lower cost. Improper venting systems increase the risk of gas porosity in HPDC. The results show that OEE values can be higher in HPDC.

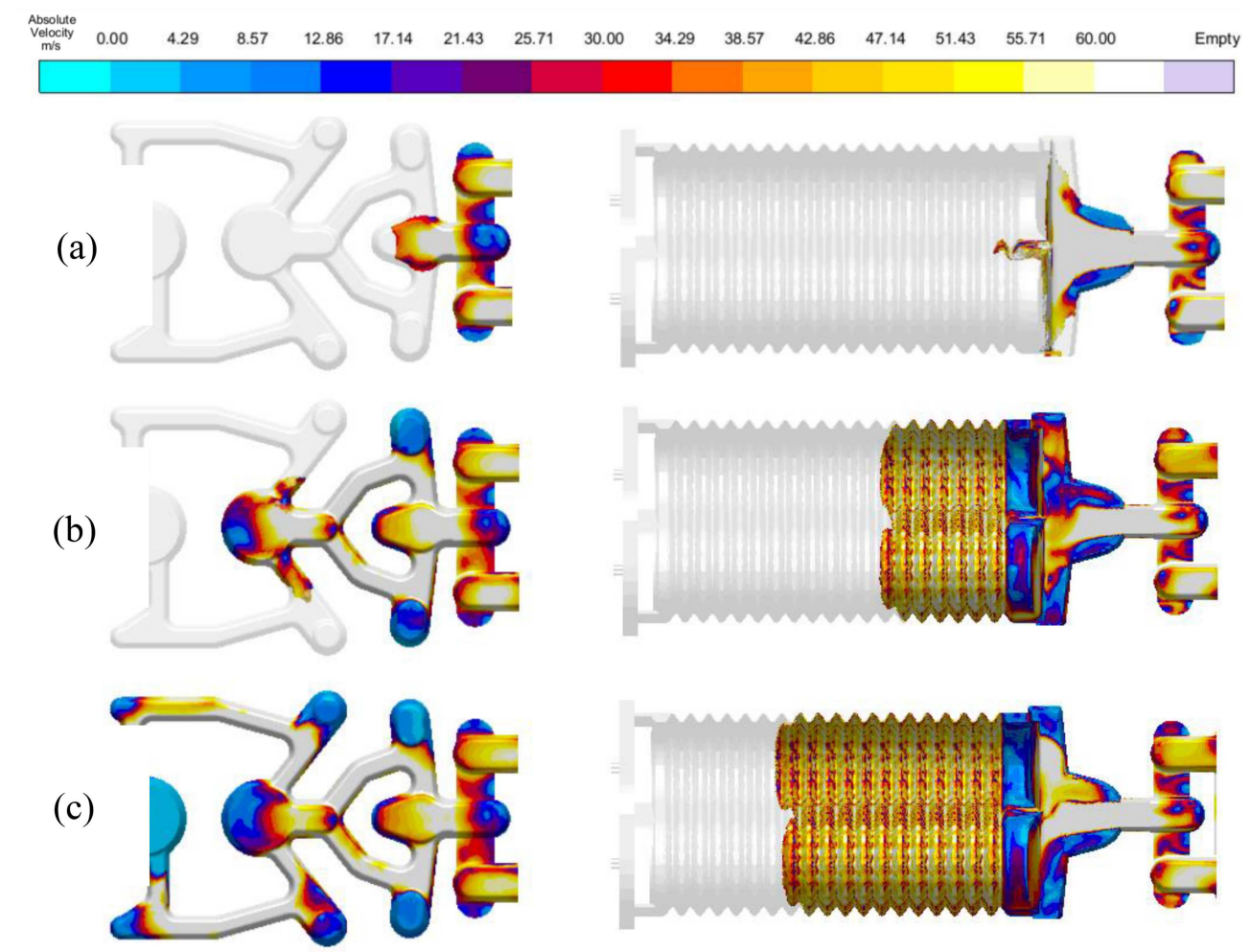

Fig. 4. Metal flow rate during filling of venting system: (a) $1 \mathrm{~ms}$, (b) $2 \mathrm{~ms}$, (c) $3 \mathrm{~ms}$ after filling of venting system. 


\section{Acknowledgments}

This work is supported with number of project 3170668 by TUBITAK 1501 . We would like to thank Fuat Topcu and Burak Erdil from Arpek for their support. We wish to thank Erhan Turkmen from Arpek due to contribution on simulation studies. Finally, thank for Murat Akçin and Gamze Kurnaz from MagmaSoft Turkey for their support.

\section{References}

[1] M.A. Irfan, D. Schwan, A. Kanve, R. Ryder, Mater. Sci. Eng. 535, 108 (2011).

[2] H. Cao, M. Hao, C. Shen, P. Liang, Vacuum 146, 278 (2017).

[3] Q. Wang, S. Xiong, Trans. Nonferr. Met. Soc. China 24, 3051 (2014)
[4] L. Wang, P. Turnley, G. Savage, J. Mater. Process. Technol. 211, 1510 (2011).

[5] J. Campbell, Complete Casting Handbook, University of Birmingham, U.K. 2011.

[6] B. Walkington, Die Casting Defects - Causes and Solutions, NADCA, 1997, p. 48.

[7] G. Savage, L. Wang, M. Gershenzon, V. Nguyen, CastExpo'05, St Louis (MO) 2005.

[8] C. Badini, F. Bonollo, M.P. Cavatorta, G.M. La Vecchia, A. Panvini, A. Pola, W. Nicodemi, M. Vedani, Metall. Sci. Technol. 20, 14 (2002).

[9] L. Wang, Int. J. Cast Met. Res. 20, 191 (2007).

[10] S. Ertürk, L. Kumruoğlu, A. Ozel, Acta Phys. Pol. A 125, 449 (2014). 